\title{
Retinal circulation during a spontaneous rise of intraocular pressure
}

\author{
JUAN E GRUNWALD, CHARLES E RIVA AND DAVID M KOZART \\ From the Scheie Eye Institute, Department of Ophthalmology, School of Medicine, University of Pennsylvania, \\ Philadelphia, PA 19104, USA
}

SUMMARY The retinal haemodynamic changes occurring in an eye with a spontaneous elevation of intraocular pressure were investigated by bidirectional laser Doppler velocimetry and monochromatic fundus photography. At an intraocular pressure of $47 \mathrm{mmHg}$ the blood velocity and volumetric blood flow rate were significantly smaller and arterial blood velocity pulsatility was significantly greater than normal. The corresponding $88 \%$ reduction in perfusion pressure was accompanied by a $67 \%$ reduction in total retinal blood flow, indicating that autoregulation is not efficient at this level of intraocular pressure. An Octopus visual field examination obtained immediately following blood flow measurements suggested that the central retina can preserve a fairly good function under a total retinal blood flow rate of about one-third of the normal value.

The effect of an increased intraocular pressure (IOP) on retinal blood flow has been studied previously. ${ }^{1-11}$ While some investigators have shown that retinal blood flow is maintained by autoregulation over a wide range of elevated IOPs, ${ }^{25}{ }^{211}$ others have found that blood flow is decreased at IOPs above $27-30 \mathrm{mmHg} .{ }^{6-9}$

In contrast to previous animal and human studies in which IOP has been artificially raised for short periods of time by cannulation of the anterior chamber or by application of a suction cup, this report describes retinal blood flow measurements obtained in an eye with a spontaneous and more prolonged elevation of IOP. These measurements were obtained by a combination of bidirectional laser Doppler velocimetry (BLDV) and monochromatic fundus photography.

\section{Materials and methods}

CASE REPORT

The patient studied was a healthy 25 -year-old white male with nothing relevant in his medical or family history except for the occurrence of glaucoma in a paternal grandfather. The patient received routine ophthalmological care from age 6 to 20 , and the results of his examinations were always within

Correspondence to Dr Juan E Grunwald, Scheic Eyc Institute 51 North 39th Street, Philadelphia, PA 19104, USA. normal limits. The IOP recorded in his late teens was $20 \mathrm{mmHg}$ in both eyes.

The patient's first significant visual complaints occurred at age 25 . On repeated occasions following vigorous games of basketball he noted a fuzziness in his temporal field of vision in both eyes. An ophthalmic examination revealed a visual acuity of $6 / 5$ in both eyes and IOPs of $23 \mathrm{mmHg}$ in the right eye and $26 \mathrm{mmHg}$ in the left eye (Goldmann applanation tonometry). On slit-lamp examination marked iris transillumination was observed in both eyes. A faint Krukenberg spindle was noted in the left eye. None was noted in the right eye. Gonioscopy showed very wide open angles, with minimal pigmentation in the right eye and heavy pigmentation in the left eye. Ophthalmoscopy revealed a cup to disc ratio of 0.4 in the right eye and $0 \cdot 3$ in the left eye. An octopus visual field (program 32) was within normal limits.

The patient was re-examined immediately after a vigorously played game of basketball. Ten minutes after the conclusion of the basketball game the IOP was $21 \mathrm{mmHg}$ in the right eye and $29 \mathrm{mmHg}$ in the left eye. No cells were noted in the anterior chamber of the right eye. Pigmented cells $(+2$ to +3$)$ were noted in the left eye. Forty minutes after the conclusion of the basketball game the IOP was $28 \mathrm{mmHg}$ and 34 $\mathrm{mmHg}$. In the interval between these two intraocular pressure measurements the patient consumed approximately one quart $(1.1 \mathrm{l})$ of water. At 120 
minutes after the basketball game the pressure was $20 \mathrm{mmHg}$ and $47 \mathrm{mmHg}$. At this pressure central retinal artery pulsations were noted in the left eye, and the patient described a greying vision in the left temporal periphery.

After an explanation of the procedures, informed consent was obtained and retinal blood flow measurements by BLDV and monochromatic fundus photography were performed. Immediately after these measurements an Octopus visual field test (program 32) of the left eye was done. This test showed a mild depression of the superior periphery, with a mean sensitivity of $26 \cdot 2$ (SD 4$) \mathrm{DB}$, a mean defect of $2 \cdot 85$ (SD 2.8) DB, and no localised visual field defect. The IOP measured in the left eye at the end of the visual field test was $50 \mathrm{mmHg}$. The brachial artery blood pressure was $125 / 75 \mathrm{mmHg}$. The IOP was returned to normal with acetazolamide $250 \mathrm{mg}$ and timolol $0.5 \%$.

Treatment was instituted consisting of one drop of pilocarpine $0.5 \%$ in each eye instilled one hour before playing basketball. On this therapeutic regimen the patient has experienced no further episodes of blurred peripheral vision. Examination after a game of basketball, with the use of pilocarpine, revealed no increase in intraocular pressure.

Retinal blood flow measurements were repeated three months later. At this time the visual acuity was $6 / 5$ and the IOP was $19 \mathrm{mmHg}$ in both eyes. No medication had been taken in the month preceding this visit.

\section{METHODS}

After pupillary dilatation with tropicamide $1 \%$ and neosynephrine hydrochloride $10 \%$, a Polaroid colour fundus photograph of each disc was taken. BLDV measurements of the maximum or centreline velocity of red blood cells $\left(\mathrm{V}_{\max }\right)$ were obtained from major retinal vessels in both eyes, as previously described. ${ }^{112}$ For later reference the exact location of the measurement sites was marked on a Polaroid photograph.

$\mathrm{V}_{\max }$ was determined according to the relation $\mathrm{V}_{\max }=\mathrm{K} \Delta \mathrm{f}$, where $\mathrm{K}$ is a constant related to the scattering geometry and the wavelength of the laser light, and $\Delta f=f_{1 \max }-f_{2 \max } \cdot{ }^{112}$ The cutoff frequencies of the Doppler shift power spectra recorded simultaneously in two different directions of the scattered light are $f_{1 \max }$ and $f_{2 \max }$. In veins 10 pairs of power spectra were used to calculate an average $\Delta f$ from which $\mathrm{W}_{\max }$ was obtained." Each of these spectra was recorded for $150 \mathrm{~ms}$ at random phases of the heart cycle and during different heart cycles. In arteries the pulsatility of $V_{\max }$ was defined as:

$$
V_{\text {max }, \text { syst }} / V_{\text {max.diast }}=f_{1 \text { max.syst }} / f_{1 \text { max.diast }} \text {, }
$$

and was calculated for each artery by averaging the ratio $f_{1 \text { max.syst }} / f_{1 \text { max.diast }}$ obtained from an average of seven different cardiac cycles. $f_{1 \text { max.syst }}$ and $f_{1 \text { max.diast }}$ are the $f_{1 \max }$ recorded during systole and diastole, respectively. Since the alignment of the fundus camera does not change during a heart cycle, Doppler power spectra recorded in only one direction of the scattered light are sufficient for the calculation of pulsatility.

To determine the change in red blood cell velocity during the heart cycle, the spectrum analyser was activated for $0.05 \mathrm{~s}$ at various phases of the cardiac cycle by means of an electronic gating module fed by the signal from a finger plethysmograph.

The cutoff frequencies of the Doppler shift power spectra were determined by visual inspection by an examiner who was masked with regard to the clinical condition of the subject studied and to the actual IOP at which the determinations had been made. Following BLDV measurements, fundus photographs were taken in monochromatic light at $570 \mathrm{~nm}$ with a Zeiss fundus camera and Kodak Plus X panchromatic film.

The diameter (D) of veins and arteries at the site of the BLDV recordings was measured from projected photographic negatives with a calliper. Determinations of $\mathrm{D}$ were obtained from an average of the diameters measured from three photographs.

Owing to technical problems with the camera we obtained monochromatic photographs of only the upper hemisphere of the left eye on the visit at which the IOP was raised. Comparison of the diameters of five major vessels (three veins and two arteries) of the superior hemisphere between the two measurement sessions showed an average difference of only $0 \cdot 16 \%$ (percentage changes of the diameter of the veins were $+1.5 \%,-2.6 \%$, and $-0.5 \%$, and in the arteries were $+1 \cdot 8 \%$ and $-1.0 \%$ ). Therefore, in the calculation of blood flows for the vessels of the lower hemisphere in which D could not be measured, we used the values of $D$ determined from photographs obtained at normal IOP.

The retinal volumetric blood flow rate, $\mathrm{Q}$ was calculated from the relation:

$$
\mathrm{Q}=\mathrm{V}_{\text {mean }} \cdot \frac{\pi \mathrm{D}^{2}}{4}
$$

where $V_{\text {mean }}$ represents the mean velocity of whole blood. We have assumed that $\mathrm{V}_{\text {mean }}=\mathrm{C} \cdot \mathrm{V}_{\text {max }}$, with $\mathrm{C}$ being a constant which is the same for all vessels measured. In this study we adopted a value of $\mathrm{C}=1 / 1 \cdot 6$, based on the work of Damon and Duling. ${ }^{13}$ The exact value of $C$ was not so important, since we were mainly interested in the changes in blood flow during elevated IOP.

IOP was determined by Goldmann applanation tonometry after the instillation of two drops of 
proparacaine $\mathrm{HCl} 0.5 \%$. The brachial artery blood pressure was measured by sphygmomanometry.

The ophthalmic artery blood pressure was measured using compression ophthalmodynamometry. The IOP obtained during the application of a dynamometer force equivalent to the diastolic and systolic ophthalmic artery blood pressures was determined by applanation tonometry and recorded as $\mathrm{OABP}_{d}$ and $\mathrm{OABP}_{\mathrm{s}}$. The mean ophthalmic artery blood pressure $\left(\mathrm{OAPB}_{\mathrm{m}}\right)$ was calculated according to the formula $\mathrm{OABP}_{\mathrm{m}}=\mathrm{OABP}_{\mathrm{d}}+1 / 3\left(\mathrm{OABP}_{\mathrm{s}}-\right.$ $\left.\mathrm{OABP}_{d}\right)$. Perfusion pressure (PP) was calculated as the $\mathrm{OABP}_{\mathrm{m}}-\mathrm{IOP}$.

$\mathrm{OABP}_{m}$ was measured only during the session in which resting IOP was normal. We have assumed in our calculations that $\mathrm{OABP}_{\mathrm{m}}$ was not different during the other measurement session from the fact that the mean brachial blood pressure did not change between the two occasions.

\section{Results}

Determinations of retinal vessel diameter, red blood cell velocity $\left(\mathrm{V}_{\max }\right)$ and volumetric blood flow rate obtained at normal IOP $(19 \mathrm{mmHg})$ and elevated IOP $(47 \mathrm{mmHg})$ in the left eye are shown in Table 1 . The exact locations of the measurements are depicted in figs $1 \mathrm{~A}, \mathrm{~B}$.

At elevated IOP, the venous volumetric blood flow rate and venous $\mathrm{V}_{\max }$ were significantly decreased (Table 1). The total venous volumetric blood flow calculated by summing the flows in the individual major veins decreased by $67 \%$ from 31.0 (SD 5.0 ) $\mu \mathrm{l} / \mathrm{min}$ to $10 \cdot 1$ (SD 2.3) $\mu \mathrm{l} / \mathrm{min}$.

In the right eye the sum of the venous volumetric flow rates measured in the three major retinal veins at normal pressure was 25.6 (SD 4.9) $\mu \mathrm{l} / \mathrm{min}$. As can be seen in Fig. 1, measurements of volumetric flow rate in the lower nasal vein were not performed. In this vessel a flow of $7 \mu \mathrm{l} / \mathrm{min}$ was estimated from the relationship between diameter and flow in normal eyes (Riva et al." Fig. 4). From the measurements of the three major veins mentioned above and the estimation of flow in the lower nasal vein, we calculated a total venous volumetric blood flow rate of $32 \cdot 6 \mu \mathrm{l} / \mathrm{min}$.

At increased IOP, the velocity pulsatility measured from the lower temporal artery $(10.2$ (SD 2.6)) was significantly larger than normal (3.08 (SD 0.4)) Student's $t$ test, $\mathrm{p}<0.001$.

In the two arteries measured in the right eye at normal IOP (Fig. 1), vessel diameter (146 (SD 4) $\mu \mathrm{m}$ and 145 (SD 3) $\mu \mathrm{m}$, respectively), and pulsatility (2.94 (SD 0.29) and 2.92 (SD 0.33)) were within the range of those measured in the left eye under similar conditions.
Table 1 Retinal blood flow measurements in the left eye at normal and elevated intraocular pressure (IOP)

\begin{tabular}{|c|c|c|c|}
\hline & $\begin{array}{l}\text { Measurements } \\
\text { at normal IOP } \\
\pm S D\end{array}$ & $\begin{array}{l}\text { Measurements } \\
\text { at elevated IOP } \\
\pm S D\end{array}$ & $\begin{array}{l}\text { Percentage } \\
\text { change }\end{array}$ \\
\hline $\begin{array}{l}\text { IOP }(\mathrm{mmHg}) \\
\text { BABP }(\mathrm{mmHg}) \\
\text { OABP }(\mathrm{mmHg}) \\
\text { PP }_{m}(\mathrm{mmHg})\end{array}$ & $\begin{array}{l}19 \\
124 / 76 \\
66 / 44 \\
32\end{array}$ & $\begin{array}{c}47 \\
120 / 78 \\
- \\
4\end{array}$ & $\begin{array}{c}+147 \\
- \\
-88\end{array}$ \\
\hline $\begin{array}{l}\text { Vein } 1 \\
\text { Diameter }(\mu \mathrm{m}) \\
V_{\max }(\mathrm{cm} / \mathrm{s}) \\
\mathrm{Q}(\mu \mathrm{l} / \mathrm{min})\end{array}$ & $\begin{array}{c}169 \pm 4 \\
1 \cdot 41 \pm 0 \cdot 36 \\
11 \cdot 9 \pm 3 \cdot 1\end{array}$ & $\begin{array}{r}(169)^{*} \\
0 \cdot 38 \pm 0 \cdot 1 \\
3 \cdot 2 \pm 0 \cdot 8 \ddagger\end{array}$ & $\begin{array}{l}-\overline{73 \dagger} \\
-73\end{array}$ \\
\hline $\begin{array}{l}\text { Vein } 2 \\
\text { Diameter }(\mu \mathrm{m}) \\
\mathrm{V}_{\max }(\mathrm{cm} / \mathrm{s}) \\
\mathrm{Q}(\mu \mathrm{l} / \mathrm{min})\end{array}$ & $\begin{array}{c}170 \pm 3 \\
0 \cdot 94 \pm 0 \cdot 31 \\
8 \cdot 0 \pm 2 \cdot 6\end{array}$ & $\begin{array}{c}161 \pm 4 \\
0 \cdot 37 \pm 0 \cdot 26 \\
2 \cdot 8 \pm 1 \cdot 9\end{array}$ & $\begin{array}{l}-5 \\
-61 \dagger \\
-65\end{array}$ \\
\hline $\begin{array}{l}\text { Vein } 3 \\
\text { Diameter }(\mu \mathrm{m}) \\
V_{\max }(\mathrm{cm} / \mathrm{s}) \\
Q(\mu \mathrm{l} / \mathrm{min})\end{array}$ & $\begin{array}{c}132 \pm 1 \\
1 \cdot 47 \pm 0 \cdot 56 \\
7 \cdot 5 \pm 2 \cdot 9\end{array}$ & $\begin{array}{c}129 \pm 3 \\
0 \cdot 49 \pm 0 \cdot 12 \\
2 \cdot 4 \pm 0 \cdot 7\end{array}$ & $\begin{array}{l}-2 \\
-67 \dagger \\
-68\end{array}$ \\
\hline $\begin{array}{l}\text { Vein } 4 \\
\text { Diameter }(\mu \mathrm{m}) \\
V_{\max }(\mathrm{cm} / \mathrm{s}) \\
\mathrm{Q}(\mu \mathrm{l} / \mathrm{min})\end{array}$ & $\begin{array}{c}109 \pm 3 \\
1 \cdot 02 \pm 0 \cdot 23 \\
3 \cdot 6 \pm 0 \cdot 8\end{array}$ & $\begin{array}{l}(109)^{*} \\
0 \cdot 49 \pm 0 \cdot 15 \\
1 \cdot 7 \pm 0 \cdot 5 \ddagger\end{array}$ & $\begin{array}{l}- \\
-52+ \\
-53\end{array}$ \\
\hline Total venous $\mathrm{Q}$ & $31 \cdot 0 \pm 5 \cdot 0$ & $10 \cdot 1 \pm 2 \cdot 3$ & -67 \\
\hline
\end{tabular}

*These values could not be measured (see 'Methods'), and therefore, we used the results obtained during normal IOP. +Significant change by non-paired Student's $t$ test, $\mathrm{p}<0 \cdot 001$. $\ddagger$ This value was calculated from the venous diameter measured at normal IOP.

BABP indicates brachial artery blood pressure, systolic/diastolic; OABP, ophthalmic artery blood pressure, systolic/diastolic; $\mathbf{P P}_{\mathrm{m}}$, mean perfusion pressure; $V_{\max }$, centreline (maximum) velocity of red blood cells; $Q$, volumetric blood flow rate.

The changes in the red blood cell velocity during the heart cycle under normal and elevated IOP are shown in Figs, 2A, B. At high IOP the diastolic $\mathrm{V}_{\max }$ is close to zero, and the systolic peak is considerably narrower than that present at normal IOP. Ophthalmic artery diastolic and systolic blood pressures measured during the session in which IOP was normal were $44 \mathrm{mmHg}$ and $66 \mathrm{mmHg}$, respectively.

\section{Discussion}

Our results show that an $88 \%$ decrease in perfusion pressure $(\mathrm{IOP}=47 \mathrm{mmHg})$ induces a reduction in total volumetric blood flow rate of about $67 \%$. Thus the retinal vasculature behaves almost like a passive system. Under such an acute decrease in perfusion pressure a normal retina would show a reduction in blood flow of only approximately $40 \%{ }^{y}$ due to autoregulation - that is, the tendency of the retinal circulation to maintain a nearly constant blood flow in spite of changes in perfusion pressure. This suggests that under a more prolonged increase in 


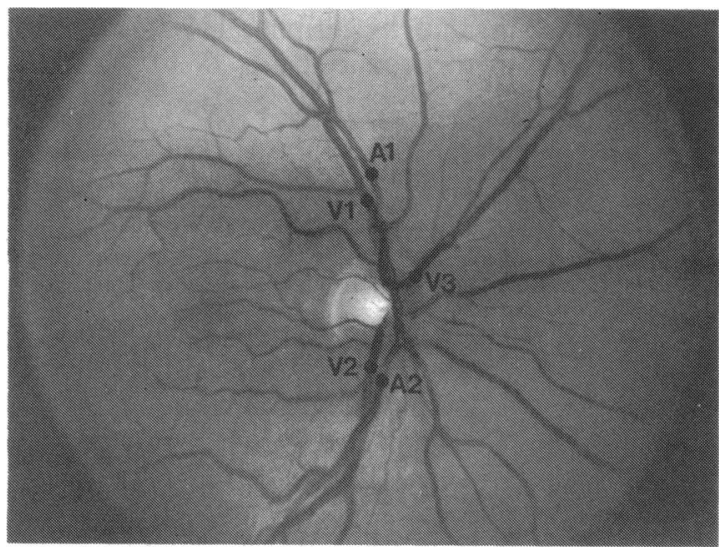

Fig. 1A

Fig. 1 Monochromatic fundus photographs of the right eye (A) and the left eye (B) obtained at normal intraocular pressure. Dots indicate measurement sites or veins $(\mathrm{V})$ and $\operatorname{arteries}(\mathrm{A})$.

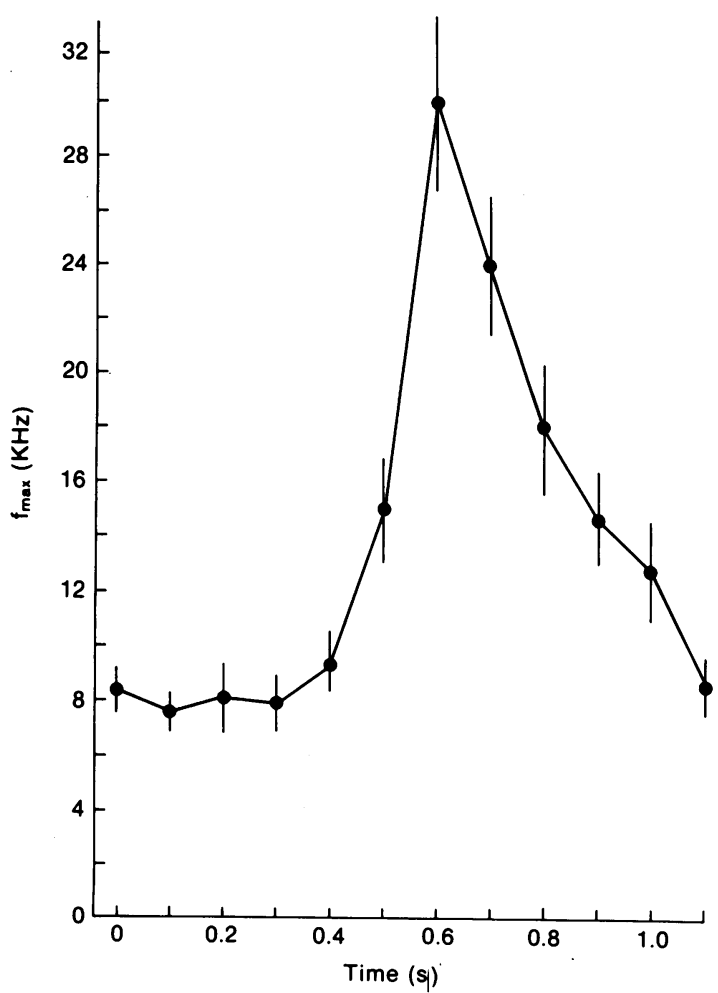

Fig. 2A

Fig. 2 Variations of $f_{\text {max }} \propto V_{\text {max }}$ during the cardiac cycle at $I O P=19 \mathrm{mmHg}(\mathrm{A})$, and at $I O P=47 \mathrm{mmHg}(\mathrm{B}) . f_{\max }$ is the cutoff frequency of the Doppler shift power spectrum recorded in one of the two scattering directions obtained during bidirectional laser Doppler velocimetry. Error bars represent \pm 1 SD based on six measurements.

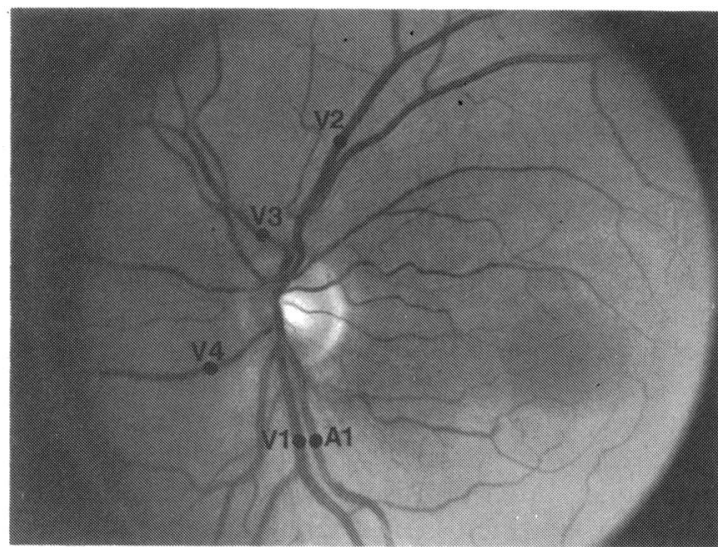

Fig. 1B

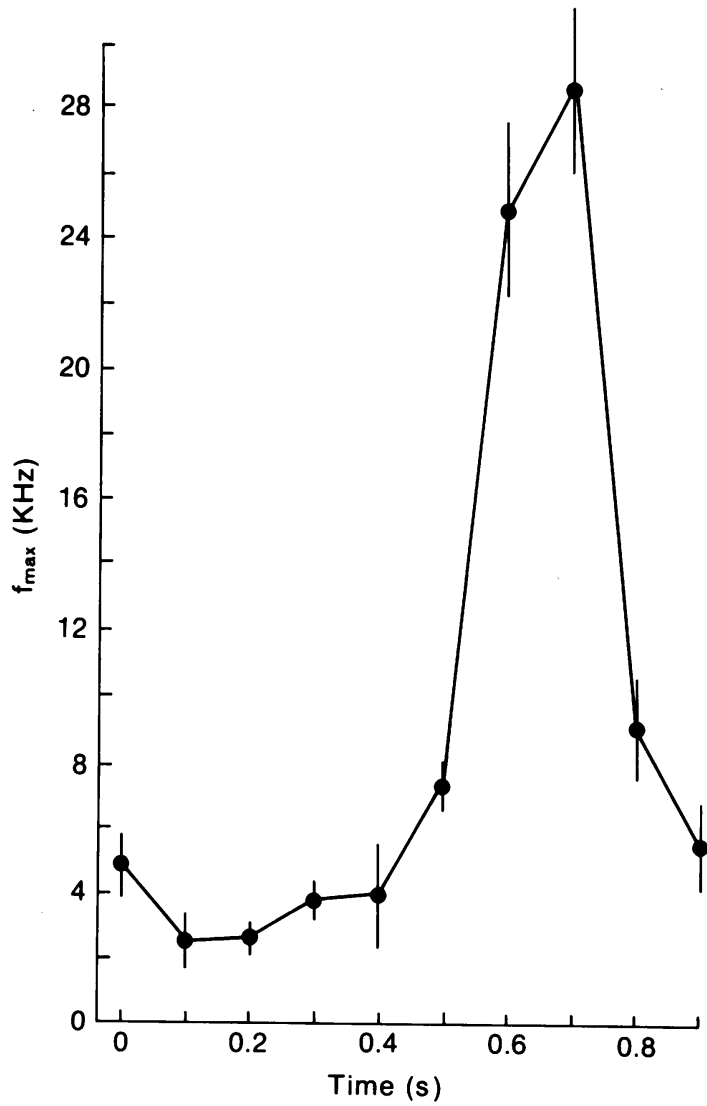

Fig. 2B

IOP the autoregulatory response may become less efficient.

As can be seen in Table 1, during elevated IOP the percentage changes in $\mathrm{V}_{\text {max }}$ and volumetric blood flow rate were smaller in vein 4 (inferior nasal) than 
in the other veins. The differences between the individual veins, however, were not statistically significant, and therefore we cannot conclude that the regulation may be more efficient in one area of the retina than in another.

The results of the present study are in accordance with previous reports in which the acute effect of a large increase in IOP was studied in the human ${ }^{6-9}$ and animal $^{13510}$ retina. The total retinal venous volumetric blood flow measured at normal IOP in the left eye $(30.8 \mu \mathrm{l} / \mathrm{min})$ is similar to that determined in the right eye $(32.6 \mu \mathrm{l} / \mathrm{min})$, and both are very close to the values reported previously in normal human retina."

Our measurements also show that under elevated IOP there is an increase in arterial velocity pulsatility. Arterial velocity pulsatility, calculated as the ratio $\mathrm{V}_{\text {max, syst }} / \mathrm{V}_{\text {max, diast }}$, increases when the IOP is raised to a level close to the ophthalmic artery diastolic pressure, because $V_{\max }$ approaches zero during diastole. This effect can be seen in Fig. 2, which shows that at an IOP of $47 \mathrm{mmHg}$ blood velocity is minimal during most of the heart cycle. Only during systole is there an increase in blood velocity for a relatively short period of time.

The case reported here has offered us a unique opportunity of investigating the retinal haemodynamic changes that occur in a human eye with spontaneously elevated IOP. In contrast to previous reports in which the IOP has been artificially elevated either by cannulation of the anterior chamber or by application of a suction cup, in the present study no manipulation of the eye was performed. In addition, the IOP in the present case remained elevated for two to three hours, allowing us to investigate the effect of a more prolonged increase in pressure than that achieved in most of the previous investigations.

It is interesting to note that, in spite of the marked reduction in retinal volumetric blood flow rate, visual field examination by Octopus perimetry revealed only a mild sensitivity depression within the central $30^{\circ}$ field, which could be due in part to the bleaching of visual pigments produced by the illumination of the BLDV instrument. This suggests that, although the retina has a high metabolic rate and a large oxygen extraction from blood, the central retina is still capable of preserving a fairly good visual field function as measured by Octopus despite a marked decrease in total retinal blood flow. The obscuration of the temporal field reported by the patient, on the other hand, shows that the peripheral visual function is not normal at this reduced rate of total retinal blood flow.

We thank Ms Joan Baine for her expert technical assistance and Ms Dolly A Scott for her careful preparation of this manuscript.

This investigation was supported by NIH Grant EY03242 and EY05775, by the Archie E Cruthirds Research Fund, and by an unrestricted grant from Research to Prevent Blindness, Inc., New York City.

\section{References}

1 Dollery CT, Henkind P, Kohner EM. Paterson JW. Effect of raised intraocular pressure on the retinal and choroidal circulation. Invest Ophthalmol Vis Sci 1968; 7: 191-8.

$2 \mathrm{~A} \operatorname{lm} \mathrm{A}$, Bill A. Ocular and optic nerve blood flow in normal and increased intraocular pressure in monkey (Macaca irus): a study with radioactively labelled microspheres including flow determinations in brain and some other tissues. Exp Eye Res 1973; 15: 15-29.

3 Ffytche TJ, Bulpitt CJ, Kohner EM, Archer D, Dollery CT. Effect of changes in intraocular pressure on the retinal microcirclulation. Br J Ophthalmol 1974; 58: 514-22.

4 Riva CE. Loebl M. Autoregulation of blood flow in the capillaries of the human macula. Invest Ophthalmol Vis Sci 1977; 16: 568-71

5 Geijer C, Bill A. Effects of raised intraocular pressure on retinal, prelaminar, laminar, and retrolaminar optic nerve blood flow in monkeys. Invest Ophthalmol Vis Sci 1979: 18: 1030-42.

6 Riva CE, Sinclair SH, Grunwald JE. Autoregulation of retinal circulation in response to decrease of perfusion pressure. Invest Ophthalmol Vis Sci 1981; 21: 34-8.

7 Grunwald JE, Riva CE, Stone RA, Keates EU, Petrig BL. Retinal autoregulations in open-angle glaucoma. Arch Ophthalmol 1984; 91: 1690-4.

8 Petrig B, Werner EB, Riva CE. Grunwald JE. Response of macular capillary blood flow to changes in intraocular pressure as measured by the blue field simulation technique. In: Heijil A, Greve EL, eds. Proc 6th Int Visual Field Symposium. Dordrecht, Junk, 1985: 447-51.

9 Riva CE, Grunwald JE, Petrig BL. Autoregulation of human retinal blood flow: an investigation with laser Doppler velocimetry. Invest Ophthalmol Vis Sci 1986; 26: 1705-12.

10 Sossi N, Anderson DR. Effect of elevated intraocular pressure on blood flow. Occurrence in cat optic nerve head studied with iodoantipyrine I 125. Arch Ophthalmol 1983; 101: 98-101.

11 Riva CE, Grunwald JE. Petrig BL. Sinclair SH. Blood velocity and volumetric flow rate in human retinal vessels. Invest Ophthalmol Vis Sci 1985; 26: 1124-32.

12 Grunwald JE, Riva CE, Sinclair SH, Brucker AJ, Petrig BL. Laser Doppler velocimetry study of retinal circulation in diabetes mellitus. Arch Ophthalmol 1986; 104: 991-6.

13 Damon DN, Duling BR. A comparison between mean blood velocities and center-line red cell velocities as measured with a mechanical image streaking velocimeter. Microvasc Res 1979; 17: 330-32.

Accepted for publication 17 July 1987. 